\title{
Legal Value of the International Rules of Law of Social Security in the Context of Protection of Labor Migrants During Pandemic COVID-19
}

\author{
Ulia U. Izvarina*, Tatiana V. Erohina
}

\author{
Department of the Labor Law, Saratov State Law Academy, 410056 Saratov, Russia \\ *Corresponding author.Email: caramelk@yandex.ru
}

\begin{abstract}
In the article the question on the global influence of the pandemic of new coronavirus infections, arisen in 2020 , on changes in the social-legal status in migrants and their families is considered. There is a necessity of careful application of the international rules of law of social security, including Conventions and Recommendations of the International Labor Organization. The rights of migrants concerning protection, ratification of the basic Conventions, concerning basic ideas of international law in the field of a regulation of social security of workers-migrants are analysed. In the course of the research the general scientific dialectic method of knowledge, a rather-legal, legallistic method have been used. The basic method of research is the system analysis of the international and national approach to a problem of access of migrants to medical aid and treatment taking into account the new global calls connected with pandemic COVID-19 acts. The influence of world pandemic new coronavirus infections COVID-19 on economic, social and political conditions in the world community as a whole is evident. Migratory processes inside each of the countries including Russia have appeared in crisis position because of closing borders and introduction of a mode of self-isolation, absence of uniform international approaches to new global calls of the present. During the research the authors come to the conclusion that formation of new social communications should promote development of uniform norms and concepts with international law of the social security, migrants concerning health services and their families. Also necessity of modification of existing procedure of granting of emergency medical aid for migrants in territory of the Russian Federation is considered.
\end{abstract}

Keywords: worker, migrant, pandemic, medical aid, public health, patent, inclusive, status

\section{INTRODUCTION}

Distribution of a new infection which on the displays is similar to seasonal cold, but leads to heavy complications, has taken mankind unawares. Not only inhabitants, but professionals of public health services and the government could not reconcile that a unique sign of probably infected person is its arrival from places where illness extends. In all countries, the developed systems of public health services changed in the Organization medical care in the pandemic period of infections.

The cores are: the essential strengthening of infectious service directed on its overcoming low priority (all countries fast rates increase an infrastructure of the infectious help), considerable expansion of capacity of hospitals for struggle with COVID-19 at the expense of creation of new hospitals, reshaping of the available; expansion of a primary link funcionality of public health services. In this sector of public health services, the basic amount of work on diagnostics of disease, rendering of the primary help, supervision over patients and their contacts is carried out.
There is a sharp increase of a role of digital medicine, including telemedical services; mobilisation of additional personnel resources, including medical. New organizational forms of rendering of medical aid are used. There is a wide attraction of possibilities of a social service and resources of local authorities.

In Russia the wide set of mobilisation actions for struggle with coronavirus with participation of the medical organizations of all kinds of medical aid and patterns of ownership is realised. The priority is given to escalating hospital beds fund of infectious service, to its technical and personnel equipment [1].

\section{MATERIALS AND METHODS}

In the course of research the general scientific dialectic method of knowledge, and also rather-legal, legallistic methods have been used. The basic method of research has been the system analysis of the international and national approach to a problem of access of migrants to medical aid and treatment taking into account the new global calls connected with world pandemic COVID-19 acts. 


\section{RESULTS}

The international organization on migration identifies some challenges for migrants in the context of distribution COVID-19. The first one is the access to the system of services of public health.

In many countries, migrants, especially in cases of stay in the country under short-term visas or in other non-standard situations, cannot get access to public health services on a level with citizens. In similar conditions, it is important to provide access to medical services for all groups of the population, including migrants. It is necessary to eliminate existing barriers and to create possibilities for carrying out of inspections and testing in areas of their residing (for example, to develop mobile medical institutions) [2].

The second challenge is residing conditions. Worldwide migrants live in the overpopulated environment with the limited access to water and hygiene means. In such conditions, it is difficult to observe principles of a social distance and other basic preventive measures, for example, self-isolation in case of illness.

For the decision of similar problems, the countries should include migrants in programs of time granting of habitation, to improve conditions of their stay and access to medical services in transit points and the reception centres. Especially sharply there is a problem of childrenrefugees which mentions, according to the United Nations, about 14 million persons: 12.7 million refugees and 1.1 million applicants of a refuge [3]. Moved children possess the most limited access to preventive services, diagnostics, treatment and other necessary support. The crisis caused COVID-19, also will negatively be reflected in their safety and access to formation.

The third factor is working conditions. Migrants constitute the labor most part in spheres which continue to work during crisis: agriculture, building, logistics and delivery, dust gathering, cleaning services. Impossibility of rendering of similar services on the remote basis, the limited access to personal transport, physical contact to colleagues and clients, a lack of means of an individual defense and hygiene do similar fields of activity dangerous from the point of view of distribution COVID-19. The considerable quantity of migrants is involved in the spheres most suffered from crisis. Thereupon inclusion of migrants in government programs of support in frameworks of struggle against consequences of pandemic COVID-19 (unemployment benefits, food coupons, grants for payments on rent) is necessary.

The fourth challenge is closing of borders. Practically all countries have reacted to a threat of distribution of COVID-19 by closing borders and toughening of migratory modes. Arriving migrants are forced to observe quarantine and to remain in the overflowed transit points. On the other hand, in the countries which have closed the borders, the considerable quantity of migrants has appeared in a distress as they cannot come back home. In similar conditions of the country, they take measures on returning migrants home, the organizations of testing for a virus in entrance points, maintenance of a place of passage of quarantine with the necessary personnel and the equipment. The countries also develop programs of assisting the families of the migrants who have suffered from COVID-19. The example of the Government of Canada which has allocated 50 million Canadian dollars (36 million US dollar) for support of farmers and employers of food sphere. It is necessary for them to establish fortnight quarantine for foreign workers [4].

The fifth factor is the status of migrants. Some countries provide help starting from migrants' conformity to administrative requirements on giving and prolongation of visa documents, definitions of the status, etc. At the same time, many governments have shown flexibility concerning migratory requirements. For example, they have entered automatic prolongation of the visa or have simplified procedures of its reception; migrants have been released from payment of gathering. Similar flexibility will allow migrants to address for medical or other help more often.

For example, the authorities of Portugal have temporarily settled the status of all migrants (including applicants of a refuge) which have handed in corresponding statements to the announcement of the state of emergency on March, 18th, 2020. This time legalization is aimed at maintenance of the rights of migrants, including access to health services and social security [5].

The sixth factor is public condemnation, xenophobia and discrimination. From the beginning of flash of virus COVID-19, the set of cases of xenophobia concerning internal migrants in China, migrants from Asia worldwide, to foreigners as a whole [6] has been fixed. The wide circulation of the xenophobia statements, the raised risk of a various sort of attacks and oppressions, most likely, will lower readiness of migrants to pass inspection and the test. After returning home, migrants also face discrimination in a society in view of fears concerning pandemic COVID-19 that sometimes leads to collisions and violence [7].

The major standard role in the further overcoming of crisis on the scale of the world community belongs to the declaration of the century of the SQUANDERER about the future of sphere of work. This provides maintenance of equal possibilities and the equal reference in the sphere of work for persons with the limited possibilities and for other persons who are in situations of vulnerability [8].

\section{DISCUSSION}

For the last two decades, foreign workers became an integral part of the Russian labor market. According to professor I.V. Shesterjakova, "the international market of a labor is not simply the sum of the national markets, it represents new qualitative development of the market of a labor in the conditions of amplifying processes of internationalization of manufacture. National labor markets lose the isolation" [9] more and more. Work in Russia for millions of households in the former union republics became the important source of incomes; the potential of labor migration from the CIS countries remains high enough. 
The basic directions of a regulation of activity of workersmigrants and protection of their rights have been mentioned in international law. The International Labor Organization (ILO), realizing the normative function, in the certificates defines the basic ideas of international law in the field of a regulation of social security of workersmigrants [10].

Regretfully, it is necessary to establish the fact that Russia has not joined basic certificates of ILO that considerably reduces the general level of socially legal protection migrants. That is especially shown during the periods of crisis social situations to which it is possible to carry a world pandemic.

In our opinion, in a situation of global changes, sociallegal systems of the world community, the attention to the question of the analysis of these major conventions and statement of a question on their prompt ratification by the Russian Federation are again sharply raised. The base norm of item 8 of the ILO Convention no. 117 "Social Policy (Basic Aims and Standards)" fixes the position according to which workers-migrants use protection and advantages not to a lesser degree than the workers living in areas of use of work.

The subject of the ILO Convention no. 97 «Migration for Employment Convention» fixes the major duty for the states which have accepted it. Without any discrimination, they give the immigrants lawfully residence in their territory. Conditions are not less favorable than those for their own citizens concerning social security (in the relation use: accidents on manufacture, protection of motherhood, illness, physical inability, an old age, death, unemployment and family duties, etc., covered by the social security system).

It is especially important, in the context of our research, to pay attention to the norm of item 5 of the ILO Convention no. 97. It obliges the states to provide medical services within the jurisdiction, which functions including the certificate in case of need.

At the moment of departure and on arrival, workersmigrants and members of their families are authorized to be accompanied or joined, have a satisfactory state of health. Authorities must provide for workers-migrants and members of their families necessary health services and good hygienic conditions at the moment of departure, during trip and on arrival to the sending party. We consider that optimization of the process of revealing illegal migration in the territory of Russia and acceptance of necessary measures on its reduction can be promoted by the prompt ratification of the ILO Convention no. 143 "Migrant workers (Supplementary Provisions)" as its norms oblige joined state to struggle with illegal migration

Also the major role in coordination of national systems of social security in the various states is played by the ILO Convention no. 157 "Maintenance of Social Security Rights Convention". The main objective of the given convention is in preservation of the rights of workersmigrants in the field of social security. Ratification of norms of all above-stated conventions, without doubts, would promote the best protection of the rights of labor migrants and their families, which are in the territory of the Russian Federation in restrictive measures, caused by distribution of new infections.

Introduction of a mode of self-isolation and suspension of activity of many enterprises in Russia became a strong social shock for labor migrants. The order of granting of medical aid to labor migrants in territory of the Russian Federation depends first of all on whether there is at the sojourning person a patent for labor activity, the permission to stay or residence, and also the policy of obligatory medical insurance or the policy of voluntary medical insurance. If the given documents at the migrant are absent, and available only by the migratory card, the person can rely on medical aid reception at emergency conditions menacing to a life.

According to point 3 of the Governmental order of the Russian Federation "About the statement of Rules of rendering of medical aid to foreign subjects in the territory of the Russian Federation" of March, 6th, 2013 no. 186, medical aid in the emergency of sudden sharp diseases, conditions, an aggravation of the chronic diseases representing threat to life of the patient is provided free of charge to foreign subjects by the medical organizations. Traumas concern such conditions: a craniocereberal trauma, crises of bones, bruises, dislocations, cuts, chemical and thermal burns, poisonings, consequences of road and transport incidents.

The sharp conditions connected with sharp deterioration of state of health involve heart attacks, pneumonia, aggravations of the chronic diseases accompanied by sharp deterioration of a condition and a strong painful syndrome. For example, at the presence of bilious-stone illness, stones in kidneys, aggravation of a gastritis, a stomach ulcer, intestinal impassability are conditions menacing to a life.

In the conditions of a pandemic, it is important to notice that in the given list there are no consequences of infectious diseases, which concerns the infection, which means the occurrence of difficulties at reception of free medical aid by migrants. One decision of a problem in our opinion is the creation of the uniform base of inspection of migrants and the uniform system of support of migrants that will exclude a corruption component in the scale shadow sector of medical service for foreign subjects [11]. In addition, it is necessary to regulate accurately the insurance mechanism, to receive and to analyse carefully the statistics in the sphere of additional medical insurance for foreign subjects [12].

\section{CONCLUSION}

Representatives of vulnerable groups of the population are subject objectively to a larger risk of coronavirus infection by an infection and at the same time have fewer possibilities to successfully consult with a difficult vital situation [13].

Despite the appreciable contribution of accepted measures to providing access of the specified groups of the population to qualitative public health services, formation 
and the employment, in some cases forcedly entered restrictions are a major factor of negative influence on conditions of a life of representatives of vulnerable levels of population. This causes necessity of the complex universal analysis of a policy of the governments for current conditions and coordination of efforts of the state, a society and business [14].

Ignoring the problem of distribution of COVID-19 among migrants can influence the states in overcoming the consequences of a pandemic making it less effective: greater quantity of people will be subject to infection, the mode of an extreme situation will be longer [15]. The pandemic has changed a habitual way and approaches to activity in all spheres. Taken by a society in reply to measures, crisis can put in pawn a basis for more equality and expansion of inclusive borders for the persons, being migrants [16].

These achievements can and should be kept when the world begins to return to a normal life. Negative changes of an existing social and economic situation are caused of pandemic COVID-19. It is impossible to overcome quickly. Consequences will be visible on a long time piece, and all institutes [17] will undergo the test.

In this situation it is especially important to lean not only on the decisions aimed at maintenance of current social and economic stability, but also at satisfaction of urgent requirements and providing realisation of a long-term policy of vigorous and steady restoration of economy taking into account new challenges.

\section{REFERENCES}

[1] V.V. Vlasov, S.V. Sazhina, I.M. Sheiman, S.V. Shishkin, Answers of systems of public health services to a pandemic: Russia vs. other developed countries, HSE Analytical Bulletin on the Economic and Social Consequences of Coronavirus in Russia and the World 2 (2020) 75.

[2] J. Bauomy, COVID-19 and xenophobia: Why outbreaks are often accompanied by racism, World Migration Report 2020, IOM, Geneva, pp. 102-104.

[3] United Nations High Commissioner of Refugees Pandemic COVID-19 proceeds also children-refugees require in even more support, retrieved from: https://www.unhcr.org/ru/22993-unhcr-unicef.html

[4] The globe and mail Inc. Ottawa to provide \$50million to ensure temporary foreign workers complete self-isolation period, retrieved from: https://www.theglobeandmail.com/politics/articleottawa-to-provide-50-million-to ensure-temporaryforeign-workers
[5] D. Devakumar, G. Shannon, S.S. Bhopal, I. Abubakar, Racism and discrimination in COVID-19 responses, The Lancet, 395(10231), 1194 (2020) 134.

[6] C.-K. Chan, Covid-19 and contact averse undocumented migrants, Migration Policy Institute 5 (2020) 12-17.

[7] L. Guadagno, Migrants and the COVID-19 pandemic: an initial analysis, Migration Research series 60 (2020) 34-38.

[8] H. Kenich, M. Nikac, E. Tamagno, Social Security for Migrant Workers: A Rights-based Approach, Social Protection for All Issue Brief (2020) 78.

[9] I.V. Shesteryakova, International legal regulation of work, SGAP, Saratov, 2004, 204 p.

[10] I.V. Grigoriev, Social security of workers-migrants in Russia: legal questions, Ural State Law University, Ekaterinburg, 2008, 136 p.

[11] R. Alkousaa, P. Carrel, Migrants let through 'shut' checkpoints, InfoMigrants, 15 April.

[12] N. Banulescu-Bogdan, M. Benton, S. Fratzke, Coronavirus is spreading across borders, but it is not a migration problem, Migration Policy Institute 4 (March 2020) 10 .

[13] Z.D. Berger, N.G. Evans, A.L. Phelan, R.D. Silverman, Covid-19: Control measures must be equitable and inclusive, The National Interest, 15 March.

[14] R. Crawford, A. Davenport, R. Joyce, P. Levell, Household spending and coronavirus, Institute for Fiscal Studies 4 (8 April 2020) p. 5.

[15] Social consequences of pandemic COVID-19 and inclusiveness, Digest of the Department of International and Regional Cooperation of the Accounts Chamber of the Russian Federation 1 (2020) retrieved from: http://www.ach.gov.ru/upload/pdf/Covid-19inclusion.pdf

[16] C. Bauloz, V. Zathi, D. Acosta, Migration, inclusion and social cohesion: Challenges, recent developments and opportunities, World Migration Report 2020, IOM, Geneva, pp. 167-188.

[17] H. Beech, Coronavirus finds fuel in a world of migrants, Migration Policy Institute 6 (May 2020) 34 